\title{
Commentary on Nida vs. Chomsky's Translation Theories
}

\author{
Huaizhou Mao \\ Foreign Language Department of Changji University, Changji, Xinjiang, China \\ Email:mhzmed@sina.com \\ Yingling $\mathrm{Gu}$ \\ Foreign Language Department of Changji Radio \& TV University, Changji, Xinjiang, China \\ Email: gylroom@sina.cn \\ Ming Liang \\ International Cooperative Institute of Xinjiang Agricultural \& Vocational Technical College, Changji, Xinjiang, China \\ Email: xjcjlm@126.com

\begin{abstract}
The paper intends to extrapolate the new perspective of "science" of translation as well as distinguish the differences and similarities in translation theories between Nida and Chomsky. However, the ultimate initiation zooms in the interpretations and understanding of the translation theories between the two. Both Chomsky and Nida made metaphysical claims about the object of investigation. Nida tends to reveals theoretical priorities, Chomsky's theory is similarly constructed, making the "logic" of the models similar. Nida's and Chomsky's theories are self-reflective, but Chomsky's universal forms exist at a much deeper, abstract level than Nida's kernels.
\end{abstract}

Index Terms —Nida \& Chomsky, translation theory, deep structure, surface structure, kernel structure

\section{BACKGROUND}

With the new perspective pracitsed in North American translation workshops characterized by a theoretical na'ivete' and subjective methodologies reinforcing whatever theoretical values individual translator hold, the theoretical contributions of the workshop approach summarized by Joseph Graham (1981) much that has been written on the subject of translation yields very little when sifted for theoretical substance because it has always been written as if spoken in the workshop. The personal anecdotes and pieces of advice may well provide some help, but certainly not the coherent and consistent theory required for translation. (p.23)

From the fragment cited above, it elicits the problem that troubled translation theory historically. Therefore, not only was a more systematic approach to translation needed, but the discipline appeared to have the theoretical and linguistic tools addressing it was linguistics.

In the early sixties, linguistics had little theoretical value to translation for translators, on the grounds that, linguistics had been characterized by descriptive research field where individual grammar were detailed but not compared. Meanwhile, the two significant and influential theories of grammar altered the journey of translation theory simultaneously. One by Noam Chomsky's Syntactic Structure (1957) and Aspects of the Theory of Syntax (1965), the other one by E.A Nida's Message and Mission (1960) as well as Toward a Science of Translation (1964). Obviously, Generative Transformational Grammar (GTG) by Noam Chomsky, along with its legitimacy among linguistics, lent credence and influence to Nida's "science "of translation, and further, Nida's theory in translating the Bible was also based on Chomsky's experience in his book Message and Mission. (1960)

However, Nida's theory, who claimed that the theory of his translation, was well developed before Chomsky's formulation, specified with the addition of Chomsky's transformational component. With the adoption of Chomsky's theoretical premise, his transformational rules, and his terminology, Nida's theory solidified, and the result of Toward a Science of Translating has become the "bible" not just for Bible translation, but for translation theory in general. In addition, Nida's development of a translation science in the Bible was motivated by a personal dislike for what he saw as a classical revival in the $19^{\text {th }}$ century, an emphasis on technical accuracy, an adherence to form, and a literal rendering of meaning, the moment of which was indicated by Mathew Arnold's literalism, which negatively affected Bible translation then.

As for Nida's "practical handbook" status within the branch of the field of theology called "missiology" because of diversified examples, Bible translating has generated more data in more languages than any other translation practice because it enjoys a longer history, has reached more people in more diverse cultures, and has involved more translators from different background than any other translation practice. At the same time, Nida, aware of the unsystematic nature of a practice-oriented approach, attempted to scientifically validate his methodology and apply it to translation as a 
whole. Nevertheless, his religious beliefs and missionary goals which attempt to unite people around a common belief in the inviolable word of God, although not explicitly stated, remain embedded within the scientific framework.

Noam Chomsky's theory of syntax and generative grammar was noticeable to be a theory of translation, the Generative-transformational Grammar, which is a theory of grammar by Noam Chomsky, attempted to provide a model for the description of all languages. A transformational- generative grammar tries to show, which a system of rules, the knowledge which a native-speaker of a language uses in forming grammatical sentences. The most of his theory was published in his book Aspects of the Theory of Syntax (1965), which consists of three levels of conceptualization (1) a base component made up of "phrase structure rules" that generate (2) a deep structure, which in turn is changed, via transformational rules in (3) a surface structure. (p.30, p.117)

Transformational grammarians work in various languages and continually point out structural similarities across languages. Such similarities fascinated Chomsky, too, although again he cautioned against drawing conclusion, knowing that deep structures needn't be like any existing structure. Hence, Transformational-generative Grammar by Noam Chomsky implicated that all grammar rules can be indefinitely generated into another form of rules in translating.

In conclusion, although the two theories evolved for different reason, they both assume that there exists a deep coherent and unified entity behind whatever manifestation language. Both Chomsky and Nida made metaphysical claims about the object of investigation for their respective theories. Chomsky's linguistics probed structures of the mind and changed the focus of linguistics in the modern age; Nida's translation theory probed structures common to all languages and found ways to transform those entities in differing languages.

The two approaches attempt to demonstrate different kinds of objects at the center-one arguing the existence of universal rules of grammar and universal lexical form; the other making metaphysical claims about an original divine message. Both linguistics and translation theory are revitalized by their respective theories. Chomsky's deep-structure vs. surface-structure model, his transformational rules, although monolinguistically derived, lends them to justifying a theory of translation. Whether one accepts Chomsky's beliefs on how human mind is structured or not, his deep structures, postulated to contain all the necessary syntactic as well as semantic information for a correct transformation into surface structure and interpretation, lend themselves well to the translation practitioner trying to represent an "underlying" message in a second language.

\section{NOAM CHOMSKY: “UNDERLYING” STRUCTURES}

Noam Chomsky's "underlying” structures represent a two level deep-structure and surface-structure, but his grammar complexity is more. According to his two-level structures, its model has several, the bottom of which is "initial element" ambiguously and followed by the "base component", which is consisted of two kinds rewriting rules: "phrase structure rules," which are often to all languages, and "lexical rules," which also derive from universal categories.

Specifically, that means that the phrase structure rules generate the deep structure of a sentence, which contains all the syntactic and semantic information determining its meaning. Finally, transformational rules modify the deep structure, resulting in the surface structures, which explain that all the sentences in a given language causing movement embedded in his theory which stated as the above on which is from the base to the deep structure via phrase structure rules and is from the deep structure to the surface via transformational rules. By the way, as Chomsky mentioned in his essay in 1965, the phrase structure rules portray the internalized an unconscious workings of the human mind with the deep structure determining meaning underlying sentences and sound to the surface structure.

However, the assumption of Chomsky' "underlying" structures raised enormous philosophic objects. Because they didn't find his evidence all that convincing; and because Chomsky's "empirical" evidence of language structure about how humans apply language in a social situation is not based upon living language, but on sentences found in an ideal state which means that linguistic theory is concerned with an ideal speaker-listener in a completely homogeneous speech-community, who knows its language perfectly and is unaffected by such grammatically irrelevant conditions a memory limitations, distractions, shifts of attention and interest ,and errors.... Reading between the lines, loaded with suppositions, which have shown doubt about during the past two decades, one of which is Michel Foucault, that there are two distinctions which refer to philosophical differences regarding assumptions about "human nature" involved and a generation gap regarding how the "creative speaking subject" is perceived. Edwin Gentzler said that Chomsky has only idealized the speaking subject and was awarded it with particular abilities concerning its creative ability to use language. But Chomsky didn't intervere, through process of idealization, certain usages involving "correct" formulations, which is very crucial to Foucault's understanding of the speaking subject and its underlying "nature".

Despite of this, After Babel issued by George Steiner (1975) implicated that it was important to deal extensively with Chomsky's theory and its relevance to understanding translation because of Chomsky's humanistic and on account of his deep-structure vs. surface-structure model. Therefore, Eugene Nida and Wolfram Wilss claimed unwillingly that one is just based upon a model similar to Chomsky's deep-structure vs. surface-structure, has perhaps simplified Chomsky's work and misappropriated it for his purposes and the other, the leading German translation scientist, has probably unwillingly adopted more from Chomsky that he is willing to admit, but all of them are absolutely applied a Chomskian model for their theories.

Turning back to the depth of Chomsky's deep-structure, which intends the "depth" of the formal properties, and whether the base structure and phrase structure are common property, which sounds formal universal common to all 
languages. Chomsky added that particular deep-structure of a sentence in any given language doesn't go much deeper than these formal properties and which are not specific to any particular language (Chomsky, 1965). And further, the deep-structure, by Chomsky, isn't universal, so the form of a particular language doesn't indispensably equal the form of another. Because the existence of deep-seated formal universals... implies that all languages are cut to the same pattern, but doesn't imply that there is any point by point correspondence between particular languages. It does not, for example, imply that there must be some reasonable procedure for translating between languages. (p.30)

As for generative rules assumed by Chomsky, with a formal device probably existing behind all, lie at the heart of man's language facility. Edwin Gentzler (2004) in his Contemporary Translation Theories, argued that Chomsky didn't jump to conclusions, based upon correlations between two languages and not assume that a grammar particular to one language would work systematically for another, which means that surface structures needn't be like their underlying deep structures.

Transferring to the perspective of translation practitioners, the generative transformational mode is not only separated from all the translation problems concerning Neologisms to archaisms, proper nouns to metaphors, high registers to dialects and mistakes, but also both impossible and fascinating complicated and sophisticated problems in translation. Quines pointed out that the very notion of synonyms strikes a resonant chord and is more relevant to practitioners than language theory, positing universal structures. Frankly speaking, a linguistic methodology isolating its model from spoken language is both overly idealistic and too "theoretical" for many a translator's taste. The fact is that spoken language contains "the problems" to tell the readers something about meaning and the structural nature of language. The generative transformational grammar not only to ignore all errors-"the problems" but to term them grammatically irrelevant, will perhaps obscure as much as it reveals about the structure of language.

The contributions to $20^{\text {th }}$ century thought about Chomsky's theory were apparent. Whether his generative transformational mode is of value to the translation of literature or not, Chomsky's arguments haven't persuaded everyone just as Smith doubted in his book about Chomsky's generative transformational grammar that whether linguistics is equivalent to transformational-generative grammar; whether Chomsky's theory is the most suitable model for literature translation and the pursuit of its study; whether linguistics themselves are so well established and free from internal problems or external criticize that the literary theories are well advised to adopt and apply them unreflectingly.

All in all, though enormous reservations from creative writers, Chomsky's generative transformational grammar definitely proceeded to construct science and which turned out to be the most influential approach in the field for subsequent decades.

\section{EugENE NidA: APPLYING GENERATIVE GRAMMAR TO TRANSLATION}

The obvious communication of the Christian faith and the discussion of theological motivations exposed in Nida's (1960) text Message and Mission, which means: "breaking new ground with new tools" (p.787) and which proved his religious presuppositions. So, Nida's religious beliefs tend to be very instrumental in the formation of his scientific theory of translation. Even he confused the translator's role with that of the missionary. The differences between exegesis and translation are disappearing in Nida's theory because he paid much more attention to the explanation itself than the ways of rendering the message and the things the original formation remaining.

Consequently, Nida claimed for the translators to be familiar to knowledge of source completely, even requires the same "empathetic" spirit. In other words, Nida's "empathetic"spirit approximately approaches total devotion to and dependence upon the original author's intent. But Nida's intentional fallacy was criticized because "what a work says and what the author intended it to say are two different things". Naturally, Nida's theory of translation seems less scientific motivated and more a positive reaffirmation of the work than relevation by the God invisible in original message taking on archetypal status.

As it was said above, Nida never took communication for granted by employing all the resources of linguistics, so he drew conclusion that why the religious message often failed to be communicated is that they ignored the different cultural contexts and world views. Thus, meaning can't be separated from personal experience and the conceptual framework of the person for message-ideas to fit with the conceptual map of experience of the different context. In other words, Nida introduced a culture remote from his own to his practical experience in introducing new ideas. That is the cultural context in which the communication occurs.

Though supportive by referring to communication theory and sybernetics by Nida, it is not only pragmatically motivated, but rooted in Nida's religious presuppositions because, for pragmatic and theological reason, Nida shows a strong interest in the response of the person receiving the communication.

Theoretically, Nida just privileged the sign as a kind of response and it is successful that it can elicit the response God intends. Thus, words and symbols are only labels, which will place the form of the message in the secondary status. As it is known that Nida's primary intended to concern the functions of sign in any given society. In that case, these "functional definition of meaning" marks an advance over traditional mentalistic and imagistic definitions of meaning and his pragmatic interests appear to be at least a deviation from more traditional notions of deep structure.

Concretely, Nida's theory factors more the context of the message. Nida noted that the translated text should release a response in a reader in today's culture, which supposed not to be like the original receptors, making changes in the text to solicit that initial response. But his theory of "dynamic equivalence" is less derived from scientific principles and is 
more an outcome of the nature of his religious inclinations. So Nida's translation becomes the rearticulation of the power of the word.

As it was cited above that the functional definition of meaning "an advance and a deviation from traditional notions of deep structure for Nida's pragmatic interests. Nida's pragmatic concept of deep structure, differentiating from Chomsky superficially, because the pragmatic aspect of meaning is factored into the structure, not at the surface level, but at the base, Nida's base naturally has a dual nature one of which is a core of syntactic structures and the other of which is of universal human experience to accomplish this difficult schema structures. Here, expanding the nature of the core of his theory, including a "universal experience of receiving the message, including a reception component in the base component, will be obvious. Furthermore, Nida argued that the deep structure of the language composed of the sign in context, can be deducted study of language and culture and through exegesis of these signs. Only then can the appropriate response to that structure be determined and universalized. In conclusion, Nida concentrates not formal correspondence, but functional equivalence; not literal meaning but dynamic equivalence; not "what "language communicates, but "how" it communicates. It is a kind of progress anyhow.

Thereby, considering that meaning in terms of its functional and abstracted the concept to the point refined by Nida, following the appropriation of chomsky's model with its concept innate structures of the mind, its "generative" rules of transformation as well as its reduction of surface sign to superficial status is quite natural. Then Nida again, summarizes some of the universals by "backing_transforming," such as subject-predicate constructions, formal distinctions between nouns and verbs, and basic object structures expressed by nouns and events by verb. Hence, Nida compares the theoretical possibilities for diversities of language structures which include remarkably similar kernel structure developed by permutations; and which include a high degree of parallelism between formal classes of words on their simplest structural levels. (Nida, 1964). If so, though Nida's different interest and goals widely from Chomsky, the two reach similar conclusion about the nature of language, positing the existence of deep structures underlying all surface structures.

Methodologically, comparing differences between Nida and Chomsky, Nida tends to backwards form the surface to the original text to its deep structure, to transfer that deep structure to the deep structure of new language, and then to generate a surface structure in the second language from a decoding and recoding process where the original message never changes. In summarize, scientifically and practically more effective to reduce the source text to its structurally simplest and most semantically evident kernels; to transfer the meaning from source language to receptor language on a structurally simple level; to generate the stylistically and semantically equivalent express in the receptor language and to test the translated text with persons representing the intended audience (Nida, 1964).

Although working backwards and reducing texts to simple structural sentences and most evident kernels are not Chomskian procedures but a misappropriation. So "back-transferring", revealing universals of syntax and semantics, arouse doubts about Nida's concept of transformational rules in General.

\section{Conclusion}

Traveling through literature review about E. A. Nida and Noam Chomsky, the differences and similarities between the two are half done according to their theories of translation. If Chomsky's theoretical base is Platonic, Nida-Protestant.

Concerning the depth of common property, Chomsky viewed that formal properties go much deeper than the particular deep structure of a sentence in any given language and he doesn't think deep structures are universal. But Nida's deep structure, underlying a sentence in two particular languages, appears not to be evident.

Before Chomsky's generative rules, at the heart of man's language facility and a formal device behind all languages, especially correlations between just two languages, haven't shaped initially, Nida derives a transformation procedure based on Chomsky's simplized notion. And it was not the deep phrase structure rules considering real structural diversity and surface different that Chomsky focuses. He zooms primarily the deep structure, transformational rules and surface structure similar across language.

Nida's moving in the direction of a scientific analysis "breaking new ground with new tool" (p.44) reveals his communication of the Christian faith, the discussion of theological motivations, comparing with Chomsky are, on the contrary, evident. Nida just privileges the reponse to the sign which intends that words and symbols are only labels. Whereas, Chomsky shows doubt about Sapir-whorf's approach to linguistic because of too specific to investigate the meaning inherent in the sign separated from cultural context. Nida's concerning is how the sign functions in any given society, which he claims that the "functional definition of meaning" marks an advance. But Nida's pragmatic interest appears to be at least a deviation from more traditional notions of deep structure.

Nada's concept of meaning, the base of which is a dual nature-a core syntactic structures and of universal human experience to expand the nature of the core of his theory to include a universal experience, while Chomsky's concept of deep structure is just adding to it.

The similarities in diversity lie of structures of language. Nida thinks that remarkably similar kernel structures from which all the structures are developed by permutations, replacements, additions and deletions and on their simplest structural levels a high degree of parallelism between formal classes of words (Nida, 1964); Chomsky's theory involved three levels of conceptualization which respectively is a base component made up of "phrase structure rules" that 
generate a deep structure, which in turn is changed, via transformational rules, into a surface structure.

Both Chomsky and Nida made metaphysical claims about the object of investigation for their respective theories. Chomsky's linguistics probed structures of the mind and changed the focuses of linguistics in the modern age; Nida's translation theory probed deep structures common to all languages and found a way to transform those entities in differing languages. The two approaches attempt to demonstrate different kinds of objects at the center which implies the existence of universal rules of grammar and universal lexical forms; the other making metaphysical claims about an original divine message.

Nida tends to backwards from the surface to the original text to its deep structure, transfer that deep structure to the deep structure of the new language, and then elicit a surface structure in the second by decoding process without changing the original message. However, Chomsky only suggests the non_ linear transformational rules. So that, it's a distortion for Nida to misuse Chomsky's theory of transformational grammar.

Elsewhere, "faithful" and "free", in tradition, respectively, has served for literal translation privileged form and used to designate those translation privileged content. Nida tends to the latter, which reveals, for proper translation, his theoretical priorities; Chomsky's theory is similarly constructed, making the "logic" of the models similar. But both Nida's and Chomsky's theories are self_reflective, the difference is that chomsky's universal forms exist at a much deeper, abstract level than Nida's kernels....

\section{LiMitaTions}

This paper focuses on the "The 'Science' of Translation", not on the field: the north American translation theory of Richards' new criticism and translation, Ezra Pound's theory of luminous details, Frederic Will's paradox of translation; polysystem theory of Itamar Even's intersystem literary relations, and Gideon Toury's target-text theory of translation and Gideon Toury's descriptive translation studies and beyond.

In the future studies, only can we round up all the aspects, we can know more about the theory of translation in the circle of translation. Much work has to be done. Although contemporary translation theory has evolved a long way since its beginnings, it now stands on the threshold of a very exciting new phase, one which can begin to unpack the relations in which meaning is constituted, and thus better inform our postmodern conception of language, literary discourse, and identity. Because we are at the verge of an exciting new phase of research for the field, one that id forcing scholars to combine theories and resources from a variety of disciplines and which is leading to multiple new insights.

\section{REFERENCES}

[1] Chomsky, N. (1957). Aspects of the Theory of Syntax. Cambridge, Mass.: The MIT Press.

[2] Chomsky, N. (1965). Syntactic Structures. The Hague: Mouton. 30; 117.

[3] Gentzler, Edwin, (2004). Contemporary Translation Theories ( $2^{\text {nd }}$ Ed.). Shanghai: Shanghai Foreign Language Education Press. $1-15$.

[4] Graham, Joseph F, (1981). "Theories for translation" in Marilyn Gaddis Rose (ed.). Translation Spectrum: essays in theory and practice. Albany: State University of New York Press. 23.

[5] Steiner, George. (1975). After Babel: Aspects of Language and Translation. Oxford: Oxford University Press.

[6] Jun XU, (2003). On Translation. Wuhan: Hubei Education Press. 88-92.

[7] Richards, Jack, C. (2000). Longman Dictionary of Language Teaching \& Applied. Linguistics. Beijing: Foreign Language Teaching and Research Press. 488.

[8] Mark, Shuttleworth \& Moria, Cowie, (2004). Dictionary of Translation Studies. Shanghai \& UK: Shanghai Foreign Language Education Press \& St. Jerome Publishing House. 77; 150; 158.

[9] Nida, E, A, (1993). Language, Culture, and Translating ( $1^{\text {st }}$ Ed.). Shanghai: Shanghai Foreign Language Education Press. 116-155.

[10] Nida, E, A, (1960). Message and Mission: the Communication of the Christian Faith. New York: Harper and Brothers. XVII. 787.

[11] Nida, E, A, (1964). Toward a Science of Translation: With Special References to Principle and Procedures Involved in Bible Translating. Leiden: E. J. Brill. 68.

[12] Qing-hua FENG, (2002). A Course-book for Practical Translation. Shanghai: Shanghai Foreign Language Education Press. 44-75.

[13] Unclear. (2000). Holy Bible (new revised standard version). China: National TSPM \& CCC. 407-409.

[14] Shi-xiong MU, (2004). Thesis Writing for Graduate Students. Beijing: Beijing Foreign Language Teaching and Research Press. 48-50.

[15] Zhang-zhu GUO, (2003). A Practical Course in Translation Between English and Chinese. Wuhan: Wuhan University Press. 47-84. 


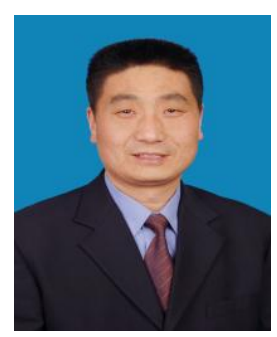

Huaizhou Mao, born in 1966-, Tianshui City of Gansu Province (China), Instructor, Double M.A Degrees, in Med. and Pedagogy, is now teaching in Foreign Language Department of Changji University in Xinjiang Uygur Autonomous Region. He is committed to the cause of education for 26 years, and his research field is the theories of English teaching and curriculum. His main study is concentrated on the Second language Acquisition, curriculum development, and empirical researches, especially in the statistics of the Statistic Package of Social Science (SPSS). He published one academic book in 2011, one course book, and nearly 18 articles including two in CSSCI in the journal of colleges and universities at home and abroad, hosted and took part in five research topics. He is also devoted and is devoting himself in the construction of curriculum such as the methodology of English teaching and the test of English language, and advanced English writing.

Yingling Gu, born in 1958-, Changji City of Xinjiang Uygur Autonomous Region in China, Associate Professor, B.A Degree, in applied linguistics, is now teaching in Foreign Language Department of Changji Radio \& TV University. Xinjiang. She is committed to the cause of education for 34 years, and her research field is the theories of English teaching in distance learning. Her main study is concentrated on adult English teaching in distance learning, especially in comprehensive courses. She published nearly 18 articles concluding two articles in CSSCI at home and abroad, hosted and took part in four research topics.

Ming Liang, born in 1960-, Changji City of Xinjiang Uygur Autonomous Region in China, Associate Professor, B.A Degree, in applied linguistics and translation, is now teaching in International Cooperative Institute of Xinjiang Agricultural \& Vocational Technical College. He is committed to the cause of education for 36 years, and his research field is the translation theories and applied linguistics. His main study is concentrated on the Ultra-linguistic factors and translation. He published nearly 10 articles including one in CSSCI in the journal of colleges and universities at home and abroad, hosted and took part in six research topics. He is also devoted and is devoting himself in the construction of vocational English education across international. 